\title{
A ROTINA DE ATIVIDADES INFANTIS NO AMBIENTE DOMÉSTICO
}

\author{
Mônia Coutinho \\ Universidade Federal do Rio Grande do Sul, Porto Alegre, Rio Grande do Sul, Brasil. \\ Mariele Santayana Souza \\ Universidade Federal do Rio Grande do Sul, Porto Alegre, Rio Grande do Sul, Brasil. \\ Luciana Brauner \\ Universidade Federal do Rio Grande do Sul, Porto Alegre, Rio Grande do Sul, Brasil. \\ Nadia Cristina Valentini \\ Universidade Federal do Rio Grande do Sul, Porto Alegre, Rio Grande do Sul, Brasil.
}

\begin{abstract}
Resumo: Crianças necessitam de práticas motoras diversificadas no seu cotidiano; familiares e/ou cuidadores desempenham importante papel neste processo. $\mathrm{O}$ objetivo do estudo foi comparar a rotina de atividades infantis no contexto familiar de meninos e meninas. Participaram 32 crianças com idades entre 5 e 7 anos. O questionário de Serrano e Neto (1997) foi utilizado. Meninos e meninas evidenciaram engajamento semelhantes e restritos em práticas de ampla movimentação. Para ambos os sexos, os ambientes familiares são pouco estimuladores, havendo carência de modelos favoráveis ao desenvolvimento do hábito de práticas ativas pelos responsáveis. A participação em programas esportivos que viabilizem práticas motoras diversificadas é essencial para suprir a carência motora vinda dos lares.
\end{abstract}

Palavras chave: Atividades Cotidianas. Atividade Física. Programa Educação pelo Esporte.

\section{Introdução}

A família é o primeiro ambiente social que a criança se insere, sendo considerado um contexto sociocultural essencial para o desenvolvimento infantil (DESSEN; POLONIA, 2007; RODRIGUES; PESSOA; SILVA, 2007; RUBINSTEIN; RAMALHO; NETTO, 2002). O ambiente familiar é capaz de modelar o comportamento da criança em relação à identificação com diferentes atividades (DESSEN; POLONIA, 2007; RODRIGUES; PESSOA; SILVA, 2007). Cada criança juntamente com sua família vivencia uma diversidade de contextos que estão em constantes interações se fazendo necessário observar a relação existente entre o indivíduo e os ambientes onde este está inserido direta ou indiretamente (BRONFENBRENNER, 1996; KREBS, 1995a, 1995b). As características individuais aliadas às características do contexto podem influenciar a trajetória como o desenvolvimento ocorre (BRONFENBRENNER, 1996; MARTINS; SZYMASNKI, 2004; NEWEEL, 1984).

É no ambiente familiar que a criança através de estímulos específicos, como o apoio social, se desenvolve. Propiciar à criança oportunidades de vivências desafiadoras é imprescindível para aquisições de novas habilidades (VALENTINI; RUDISILL, 2004a, 2004b). O contexto familiar é responsável por despertar o interesse por práticas motoras (BRAUNER; VALENTINI, 2009). Dessa forma, expor a criança a hábitos ativos pode repercutir em escolhas por atividades mais ativas na infância e ao longo da vida. Modelos 
vindos dos principais cuidadores tornam-se a influência social mais importante na vida da criança e esses desempenham papel fundamental ao promover incentivos verbais e comportamentos modelos para que seus filhos sejam ativos fisicamente (NETO, 2004; PATE; SIRARD, 2000).

Crianças e jovens apresentam em seus componentes biológicos e sociais uma grande necessidade de atividades motoras em suas vidas cotidianas, variando de contextos formais (ex.: times esportivos) a informais (ex.: recreio da escola) (NETO, 2001, 2005). Essas práticas são fundamentais para o desenvolvimento (1) das habilidades fundamentais de locomoção, estabilidade e manipulação (BRAUNER; VALENTINI, 2009; VALENTINI, 2002a); (2) do autoconceito e da motivação (ALMEIDA; VALENTINI; BERLEZE, 2009; VALENTINI, 2002b); e, (3) de habilidades sociais (NETO, 2004). A aquisições das habilidades fundamentais é fortemente estimulada por fatores ambientais (SANTOS; DANTAS; OLIVEIRA, 2004; VALENTINI; TOIGO, 2006). Portanto, é necessário que a criança seja exposta a experiências e estímulos diferenciados (RODRIGUES, PESSOA; SILVA, 2007).

Observa-se nos dias atuais uma tendência cada vez maior para adoção de padrões comportamentais familiares inativos. Atividades como assistir televisão e jogar jogos eletrônicos somadas a fatores como violência, insegurança e transporte motorizado são predominantes em relação a atividades fisicamente mais vigorosas (BARROS, 2005). Atualmente parece haver um esforço em manter a criança intelectualmente ativa e corporalmente passiva (NETO, 2005). Esses padrões menos ativos repercutem negativamente na motricidade (MALHO, 2004) e os níveis de inatividade física prevalecem entre as crianças de hoje (RODRIGUES; PESSOA; SILVA, 2007). Destaca-se ainda que existe uma espontaneidade natural da criança com as tecnologias virtuais, levando-as a brincarem menos na rua em resposta ao aumento de ofertas das atividades sedentárias, como os computadores e vídeos games (SOUZA, 1998). Jogos eletrônicos não exigem o uso das habilidades motoras amplas, permitindo o aparecimento de uma cultura motora e lúdica cada vez mais passiva, em especial nos grandes centros urbanos (NETO, 2004).

A modernidade no contexto familiar está reduzindo o exercício das capacidades físicas, motoras e perceptivas, levando crianças a apresentar dificuldades ao se movimentarem em suas rotinas diárias (MALHO, 2004; RODRIGUES; PESSOA; SILVA, 2007). Na rotina diária de crianças e jovens observa-se um aumento progressivo de inatividade física contribuindo para o aumento da obesidade infantil, diabetes e hipertensão (BERLEZE; HAEFFNER; VALENTINI, 2007). Ainda mais, percebe-se uma disposição de se preencher o tempo livre das crianças com rotinas formais, como cursos de línguas estrangeiras (NETO, 2001), diminuindo a possibilidade de práticas livres e espontâneas de jogos e atividades motoras diversificadas. O tempo e o espaço que a família possui influenciam diretamente no tempo e espaço que a criança usufrui para realizar atividades livres e espontâneas, que consequentemente conduz a ampliação do repertório motor (BERLEZE, 2002; NETO, 2001).

Os programas esportivos são meios alternativos elaborados para suprir e preencher o tempo ocioso das crianças com atividades orientadas, oferecendo aos pais uma oportunidade mais segura para a prática física. Esses projetos vem firmando-se como uma opção capaz de promover a inclusão da criança em contextos diferenciados e, principalmente, proporcionar atividades motoras distintas que estimulem o seu desenvolvimento. Na medida em que suas propostas proporcionam às crianças maiores níveis de atividade física e consequente melhora da competência motora e social (VALENTINI, 2002a; VALENTINI; RUDISILL, 2004a), as metodologias empregadas nos programas fixam-se como estratégias benéficas tanto no 
sentido social e cultural, quanto nos domínios cognitivo e motor, influenciando ganhos também na saúde.

No Brasil, muitos destes programas esportivos institucionalizados apoiam-se no caráter social, tendo como público principal a população de baixa renda. Por meio de suas propostas pedagógicas centradas no esporte educacional, esses projetos propiciam oportunidades de interação social às crianças e adolescentes (FILGUEIRA; PERIM; OLIVEIRA; 2009). Os projetos esportivos sociais repercutem positivamente na formação integral ao disponibilizar oportunidades reais para o desenvolvimento. $\mathrm{O}$ esporte educacional vivenciado nestes locais auxilia também no combate ao sedentarismo infantil presenciado na sociedade pós-moderna. Na medida em que se centra em atividades físicas visando o bem estar físico e mental da criança, o esporte educacional promove com suas metodologias a inclusão, a interação social e a aquisição de habilidades motoras e cognitivas que conduzem a melhor qualidade de vida (MELO; DIAS, 2009). Então, os programas voltados ao esporte educacional tornam-se ferramentas que oportunizam às crianças e aos adolescentes maiores experimentações das práticas diversificadas e propiciam vivências diferenciadas que conduzem a melhoras nos domínios motores, sociais e cognitivos (PALMA et al., 2009), suprindo uma possível carência nas estimulações destes domínios na rotina infantil doméstica (FILGUEIRA; PERIM; OLIVEIRA, 2009).

Partindo-se do pressuposto de que o contexto familiar pode de diversos modos influenciar positiva ou negativamente o repertório motor, cognitivo, social e afetivo das crianças, o objetivo deste estudo transversal foi analisar e descrever possíveis diferenças na rotina doméstica de atividades infantis de crianças participantes de um Programa de Educação pelo Esporte.

\section{Metodologia}

\section{Participantes}

Participaram do presente estudo 32 crianças (14 meninos e 18 meninas) com idades entre 5 e 7 anos. As crianças participavam de um Programa de Educação pelo Esporte. $\mathrm{O}$ termo de consentimento livre e esclarecido dos pais e/ou responsáveis foi obtido para cada uma das crianças participantes; o estudo foi aprovado pelo comitê de ética (número 2003109). As crianças estudavam em escolas públicas e eram provenientes de famílias de baixa renda. As crianças frequentavam o programa duas vezes na semana, onde realizam aulas com duas horas e meia de duração. As atividades visavam o desenvolvimento das habilidades motoras fundamentais e específicas de diversos esportes.

O programa tinha como enfoque os quatro pilares da educação propostos pela UNESCO: (1) aprender a conviver, sendo enfatizadas as relações interpessoais; (2) aprender a conhecer, possibilitando à criança uma aprendizagem diferenciada, autônoma e construída permanentemente; (3) aprender a fazer, baseando-se no pressuposto de renovação de conhecimentos, instigando a produção com criatividade e flexibilidade por parte do aluno; e (4) aprender a ser, unindo os três pilares anteriores para a formação de uma personalidade distinta, preparando a criança para tomar decisões e agir conforme suas escolhas (DELORS et al., 2001). Nas aulas eram utilizados estratégias de ensino voltadas para a autonomia da criança, oportunizando vivências motoras diferenciadas (SANDERS, 2005; VALENTINI; TOIGO, 2006). 


\section{Instrumento}

Para a coleta de dados utilizou-se o questionário de Serrano e Neto (1997). Este questionário possui 12 questões e engloba cinco aspectos referentes à rotina de atividades infantis: (1) gestão de tempo infantil; (2) meio de transporte utilizado para ir da casa à escola; (3) espaços destinados às brincadeiras; (4) atividades e brincadeiras mais frequentes; (5) as inter-relações - engajamento da criança com outras crianças. Berleze (2002) acrescentou um sexto e último aspecto, referente ao envolvimento familiar em atividades físicas. $\mathrm{O}$ questionário foi encaminhado aos pais/responsáveis legais para preenchimento e recolhido pelos professores do referido Programa.

\section{Resultados e Discussão}

\section{Período de Permanência na Escola}

Para a primeira questão (turno de permanência na escola) observamos um equilíbrio entre as crianças que estudam no turno da tarde (56\%) e as que estudam pela manhã (44\%). Percebe-se que um maior número de meninos estuda à tarde (64\%). Crianças que estudam pela tarde dispõem de menor tempo para brincar, principalmente devido à opção de adotarem um maior período de sono (BERLEZE, 2002).

\section{Tempo disponível para brincar}

Em relação à questão sobre o tempo disponível para brincar quando a criança não atende a escola e nem ao Programa de Educação pelo Esporte, os resultados apresentados na Tabela 1 sugerem que a maioria das crianças dispõe de mais de 4 horas para brincar diariamente; $34 \%$ dos participantes relatam brincar num período compreendido entre 3 a 4 horas. Possivelmente algumas crianças deste estudo adotem um menor tempo para brincar devido ao maior período de sono, uma vez que 56\% estudam à tarde. Estudar no turno da tarde encontra-se associado com menor tempo livre disponível para brincar (BERLEZE, 2002).

TABELA 1: Aspecto de gestão do tempo infantil: tempo livre para brincar

\begin{tabular}{lccc}
\hline Gestão do Tempo Infantil & $\%(\mathbf{N})$ & Masc $(\%)$ & Fem $(\%)$ \\
\hline Tempo livre para brincar & & & \\
< 3 horas & $16(5)$ & 7 & 22,2 \\
3 a 4 horas & $34(11)$ & 36 & 33,3 \\
> 4 horas & $47(15)$ & 50 & 44,5 \\
Sem Resposta & $3(1)$ & 7 & 0 \\
\hline TOTAL & $100(32)$ & 100 & 100 \\
\hline
\end{tabular}

\section{Meio de transporte utilizado}

Com relação aos meios de transporte utilizados pela criança para ir de casa para a escola e da escola para a casa observa-se que a maioria dos participantes realiza este trajeto utilizando meios motorizados de transporte, como ônibus e carro (47\%). Aproximadamente $44 \%$ daqueles que se deslocam de maneira não motorizada o fazem caminhando ou utilizando 
bicicletas. Dos participantes que utilizam meios motorizados $67 \%$ são meninas e $33 \%$ são meninos. Os meninos utilizam mais alternativas não motorizadas, como bicicletas e deslocamento a pé $(50 \%)$. As meninas, em sua maioria, utilizam alternativas motorizadas, como carro e ônibus (55\%). Apenas $6 \%$ dos participantes relatam utilizar as duas maneiras de locomoção. Esses resultados refletem o que pode estar relacionado ao menor nível econômico dos participantes do Programa e também a distância que a escola e o lar se encontram. Destaca-se que 3\% dos participantes não responderam a esta questão.

Outro fator que pode influenciar na escolha do meio de transporte motorizado utilizado pode ser consequência do tempo que os cuidadores das crianças dispõem para realizar o trajeto até a escola. Um possível fator agravante também envolve a segurança no momento do deslocamento, onde questões como violência e trânsito intenso são agravantes da opção de utilizar ônibus ou carro, mesmo estes representando maiores gastos familiares. Resultados semelhantes foram encontrados em outros estudos (MATSUDO et al., 2003; NETO, 2005), corroborando com a concepção de que as práticas inativas de lazer trazidas na organização familiar pela modernidade substituem o tempo disponível para as atividades físicas, afetando a vida das crianças (NETO, 2005). O aumento da densidade e das opções de transportes automotivos repercute em um estilo de vida mais sedentário para crianças (NETO, 2005). O sistema de transporte motorizado tem com a redução de gasto energético, tornando-se agravante de hábitos passivos à medida que hábitos simples, como caminhadas ou corridas, deixam de ser realizados (GUEDES; GUEDES, 1998).

\section{Espaços destinados à brincadeira}

No período em que as crianças não estão no projeto, verificou-se a pouca utilização de espaços adequados para brincadeiras livres e espontâneas. Percebe-se que os espaços criados especialmente para a prática de atividades de lazer (MARCELLINO, 2006) estão sendo cada vez menos utilizados por crianças e jovens. Os espaços usualmente não utilizados para a prática do lazer como os pátios das casas, passam a ser a alternativa mais procurada pelas famílias (MARCELLINO, 2006), fator observado no presente estudo. A criança necessita de um envolvimento diferenciado com tarefas fora de casa, oportunizando, com isso, contato com outros contextos e indivíduos e para um desenvolvimento adequado (NETO, 2004). No presente estudo essas oportunidades do brinquedo fora de casa eram limitadas a $30 \%$ da participação.

O tempo e a frequência das práticas motoras estão diretamente associados às condições dos espaços exteriores, tornando-se importante a valorização dos locais aos quais as crianças estão tendo oportunidades de brincar (NETO, 2001). Os resultados relatam que a maioria das crianças dispõe de espaços para brincar dentro de casa ou apartamento e no pátio (81\%). Aproximadamente 19\% (destes, $29 \%$ de meninos e $11 \%$ de meninas) utilizam apenas espaços fechados (somente dentro de casa ou do apartamento), sendo estes bastantes restritos para brincadeiras amplas. Os resultados apresentados na Tabela 2 mostram também que as meninas utilizam mais espaços abertos como parques do que os meninos, mas que os meninos brincam mais em espaços como ruas. 
TABELA 2: Local disponível para brincar

\begin{tabular}{lccc}
\hline Local para Brincar & \% (N) & Masc (\%) & Fem (\%) \\
\hline Só casa/apto & $19(6)$ & 29 & 11 \\
Casa/apto+pátio & $81(26)$ & 71 & 89 \\
Ruas & $12(4)$ & 14 & 11 \\
Parques & $31(10)$ & 21 & 39 \\
\hline
\end{tabular}

A diminuição das atividades em espaços abertos reflete também a preocupação da família com a violência na tentativa de proteger as crianças, sendo o espaço da mesma para o brinquedo restrito pelos pais. Uma maneira eficaz para garantir a segurança das crianças é inseri-las em práticas motoras institucionalizados para participarem de atividades programadas, como o programa de esporte aqui estudado. Nesse projeto, em especial, as crianças tinham a possibilidade de envolverem-se em práticas ativas de uma maneira mais segura, na medida em que, durante algumas horas por dia, realizavam atividades motoras sob supervisão de professores e coordenadores, tornando a utilização de espaços adequados menos restrita.

Outro fator que pode ter influenciado estes dados diz respeito à condição econômica de cada família. Famílias com maior poder aquisitivo possuem uma maior utilização dos espaços específicos de lazer, como por exemplo, os clubes e parques privados em suas moradias. Programas esportivos sociais como o do presente estudo podem ser, muitas vezes, a única possibilidade disponível das crianças para utilização de espaços específicos de lazer. A maioria das crianças não possuía hábitos de brincar em locais abertos, como parques e ruas em decorrência também do status socioeconômico de seus familiares. A sociedade pósmoderna trouxe consigo uma mudança estrutural do ambiente urbano, tornando o acesso mais difícil a espaços e equipamentos de lazer, que muitas vezes necessitam de pagamento para utilização. Essas mudanças interferem negativamente na possibilidade de diversificação dos contextos que a criança é ou será exposta, nesse sentido brincar na rua já não faz parte da vida das crianças (NETO, 2001)

\section{Frequência de Prática}

Duas questões abordaram as atividades mais praticadas e a frequência dessas práticas no instrumento utilizado. A primeira delas diz respeito às atividades mais realizadas dentro do lar e a segunda sobre as atividades de maior movimentação e sua frequência de realização. Os resultados são apresentados nas Tabelas 3 e 4.

TABELA 3: Atividades realizadas dentro de casa

\begin{tabular}{lccc}
\hline Atividades no Lar & \% (N) & Masc (\%) & Fem (\%) \\
\hline Leitura & $44(14)$ & 28 & 55 \\
Pintar e desenhar & $87(28)$ & 86 & 89 \\
Música & $44(14)$ & 50 & 39 \\
Computador & $53(17)$ & 71 & 39 \\
1 a 2 horas & & 60 & 28 \\
>2 horas & & 0 & 14 \\
TV/Vídeo & $94(30)$ & 100 & 89 \\
1 a 2 horas & & 50 & 44 \\
>2 horas & & 21 & 0
\end{tabular}




\begin{tabular}{lccc} 
Brinquedos & $84(27)$ & 64 & 100 \\
Bonecos & & 77 & 94 \\
Instrumentos & $9,3(3)$ & 7,1 & 11 \\
Tarefas de casa & $34(11)$ & 36 & 33 \\
\hline
\end{tabular}

Para as atividades mais realizadas dentro de casa, percebe-se que a maioria das crianças concentram-se em atividades de menor movimentação como, por exemplo, assistir televisão/vídeo (94\%), pintar e desenhar (87\%), brincar com brinquedos (84\%) e utilizar o computador (53\%). Todos os meninos reportaram assistir televisão/vídeo, enquanto que aproximadamente $89 \%$ das meninas reportaram que realizam esta atividade na sua rotina diária. Para ambos os sexos, o tempo médio de exposição à televisão gira em torno de uma a duas horas. Quanto aos brinquedos, os mais utilizados segundo relato dos responsáveis são bonecos e bonecas para ambos os sexos. Pelos resultados obtidos, percebe-se que as atividades mais realizadas dentro do lar pelos participantes assumem um caráter passivo. Atividades que exigem envolvimento físico mais amplo estão cada vez menos sendo vivenciadas pelas crianças e, no caso do presente estudo, encontram-se restritas à participação nos programas esportivos institucionalizados.

Desconsiderando o programa esportivo frequentado no turno inverso ao escolar, os ambientes abertos e locais como parques são insuficientes e em ambientes fechados as atividades consideradas passivas são as que mais recebem estímulos para a prática. Esses resultados são apresentados na Tabela 2. Esses resultados permitem inferir que as práticas familiares conduzem à criação de crianças corporalmente inativas, afetando principalmente a formação física e motora. O hábito de assistir televisão afeta a participação dos indivíduos em atividades físicas e estimula hábitos sedentários (BERLEZE, 2002). Salienta-se, então, a importância de proporcionar vivências que combinem atividades com diferentes graus de movimentação para proporcionar às crianças diferentes níveis de experiências motoras também dentro de casa ou do apartamento.

A Tabela 4 apresenta os resultados acerca das atividades de maior movimentação e a frequência dessas práticas pelos participantes do estudo. Essas atividades não incluem as realizadas no Programa Esportivo. É importante ressaltar que se oportunidades adequadas e diversificadas de prática não forem propiciadas, as crianças podem apresentam dificuldades motoras já nestas idades (BRAUNER; VALENTINI, 2009). A utilização das habilidades motoras fundamentais em diferentes contextos de jogo e do brinquedo de maneira proficiente só é observado se o ambiente for propício à aprendizagem e se houver exposição em experiências diversificadas (SANDERS, 2005; VALENTINI; TOIGO, 2006).

TABELA 4: Atividades de maior movimentação

\section{Atividades de Maior} Movimentação

$$
\%(\mathrm{~N}) \quad \operatorname{Masc}(\%) \quad \operatorname{Fem}(\%)
$$

\section{CORRIDA}


Diário

2 a 3 vezes/semana

Não pratica

JOGOS COM BOLA

Diário

2 a 3 vezes/semana

Não pratica

RODAS E CIRANDAS

Diário

2 a 3 vezes/semana

Não pratica

CORDA

Diário

2 a 3 vezes/semana

Não pratica

DANÇAS

Diário

2 a 3 vezes/semana

Não pratica
19 (6) $\quad 21$

17

$53(17) \quad 29$

72

$28(9) \quad 50$

11 


\section{BICICLETA}

\begin{tabular}{lccc} 
Diário & $19(6)$ & 21 & 17 \\
2 a 3 vezes/semana & $25(4)$ & 29 & 22 \\
Não pratica & $56(18)$ & 50 & 61 \\
& & & \\
\hline TOTAL & $100(32)$ & 100 & 100
\end{tabular}

Embora aproximadamente $72 \%$ dos participantes reportem participar de brincadeiras que envolvam corridas, sendo a maioria meninas, e jogos de bola (78\%), sendo a maioria de meninos, questiona-se a intensidade que estas atividades são praticadas e em que espaços as mesmas ocorrem, uma vez que as atividades de maior movimentação exigem espaços amplos para serem realizadas, e como vimos nos resultados anteriormente apresentados, o percentual de crianças que utiliza estes espaços está abaixo do esperado. Brincadeiras de rodas e/ou cirandas e bicicleta são as que menos são praticadas, com média de $34 \%$ (meninos) e $40 \%$ (meninas) de participação. Meninas praticam diariamente danças $(38,8 \%)$, enquanto o percentual de meninos que realiza esta atividade diariamente é nulo. Durante o horário em que estavam no projeto, as atividades de ampla movimentação eram praticadas de maneiras orientadas e em intensidades favoráveis ao desenvolvimento motor dos alunos, suprindo a carência existente destas práticas no ambiente doméstico.

Pode-se inferir que com as constantes mudanças e alterações existentes nas oportunidades de práticas e vivências em espaços de lazer, as meninas parecem estar aproveitando esses espaços mais frequentemente que os meninos. Conforme os resultados, as meninas são as que mais utilizam espaços abertos quando não estão nas atividades do Programa, o que pode explicar a maior frequência com que praticam as atividades de maior movimentação nestes momentos.

É visível em meios urbanos a diminuição de níveis de práticas motoras adequadas ao desenvolvimento integral e percebe-se, também, um aumento preocupante no sedentarismo infantil devido, principalmente, as oportunidades de acesso a tecnologia e às restrições sociais e culturais impostas a movimentação livre das crianças. É válido destacar que o sedentarismo é um grande fator de risco para aparição de doenças como diabetes e hipertensão. Neste sentido, hábitos sedentários adotados desde a infância conduzem a um número cada vez maior de crianças e adolescentes com níveis inadequados de saúde (BERLEZE; HAEFFNER; VALENTINI, 2007).

Relacionamento da criança com outras crianças e prática de atividade física por parte dos pais

Os resultados nos mostram que não houve relatos de crianças que brincam somente sozinhas; todos os participantes admitem brincar com crianças do bairro e/ou da escola. Aproximadamente $57 \%$ brincam com amigos da escola e do próprio bairro, 34\% com amigos 
apenas da escola e 9\% com amigos apenas do próprio bairro. Nesta questão de múltipla escolha o resultado ultrapassa o limite de $100 \%$. É válido mencionar que, aproximadamente, a partir dos 4 até os 7 anos de idade, o grupo de amigos se torna mais importante e a escola se torna uma maior fonte de socialização para a criança, que começa a buscar um maior envolvimento social (MALHO, 2004; PIAGET, 1993). Na idade dos participantes do presente estudo também se pode observar tendências de preferência por brincar com pares do mesmo sexo e idade, sendo que meninos normalmente praticam jogos envolvendo mais movimentação e meninas praticam atividades menos ativas, tendência já observada em estudos prévios (NETO, 2004).

As escolhas por brincadeiras normalmente são influenciadas pela cultura e as práticas da criança são classificadas como sendo "essencialmente masculinas" ou "essencialmente femininas" (NETO, 2004). O instrumento utilizado não verifica se os jogos e brincadeiras tem um caráter mais masculino ou mais feminino. Sugere-se que em próximos estudos, ao usar este instrumento, questões mais relacionadas ao gênero nos jogos e brincadeiras sejam inseridas para avaliar o impacto destes estereótipos sociais. Nesse sentido, o caráter social do programa em que as crianças estão inseridas atua como facilitador da interação e inclusão tanto de meninas, quanto de meninos na medida em que se trabalham estratégias inclusivas e motivadoras que minimizam diferenças culturalmente impostas entre gêneros, proporcionando oportunidades iguais de aprendizado e desenvolvimento.

Por fim, ressalta-se que a família pode ser um fator decisivo quando estimula às vivências de atividades mistas, tanto passivas quanto ativas, pois como Dessen e Polônia (2007) afirmam, a família é o primeiro mediador entre o homem e a cultura, sendo capaz de gerar modelos de relações e construções diferenciados, formando hábitos e conceitos. Portanto, no momento de oportunizar práticas diferenciadas com indivíduos diferenciados, a família exerce uma maior influência sobre as escolhas.

Como os modelos familiares são os primeiros modelos que o indivíduo tem acesso, eles possuem uma enorme influência no comportamento, especialmente das crianças (DESSEN; POLÔNIA, 2007). Portanto, o contexto de vida de cada família é fator determinante nas escolhas futuras das crianças. Neste estudo percebe-se que a maioria dos pais e das mães não pratica atividade física (pais: 46,87\%; mães: 53,12\%). A Tabela 5 apresenta os resultados referentes a essa questão.

TABELA 5: Atividade física familiar

\begin{tabular}{lccc}
\hline Atividade Física Familiar & \% (N) & Masc (\%) & Fem (\%) \\
\hline PAI & $47(15)$ & 43 & 50 \\
Não Pratica & $31,2(10)$ & 36 & 27,7 \\
a a 3 vezes/sem. & $3,1(1)$ & 0 & 5,5 \\
Diária & $18,7(6)$ & 21 & 16,8 \\
Não respondeu & & & \\
MÃE & $53,1(17)$ & 64 & 44,4 \\
Não Pratica & $34,4(11)$ & 36 & 33,3 \\
2 a 3 vezes/sem & $9,4(3)$ & 0 & 16,7 \\
Diária & $3,1(1)$ & 0 & 5,6 \\
Não respondeu & & & \\
IRMÃ̃OS & $12,5(4)$ & 14 & 11,1 \\
Não Pratica & $53,1(17)$ & 71 & 38,9 \\
2 a 3 vezes/sem & & & \\
&
\end{tabular}




\begin{tabular}{lccc} 
Diária & $6,3(2)$ & 0 & 11,1 \\
Não respondeu & $28,1(9)$ & 14 & 38,9 \\
\hline TOTAL & $100(32)$ & 100 & 100 \\
\hline
\end{tabular}

Neste estudo percebe-se que os irmãos dos participantes são os membros da família mais ativos, sendo que a maioria realiza atividades de 2 a 3 vezes na semana (53\%), tornandose assim aqueles capazes de influenciar futuramente de maneira mais positiva práticas ativas das crianças investigadas. Para os meninos, o pai e a mãe apresentaram níveis semelhantes de atividade, enquanto que para as meninas percebemos que as mães são as mais ativas.

Acredita-se que as experiências pessoais que os indivíduos tem ou terão estão diretamente vinculadas ao seu contexto de vida (BRONFENBRENNER, 1996; MALHO, 2004). Se considerarmos este pressuposto, os resultados no presente estudo tornam-se preocupantes. Se a influência para que a criança se torne adepta de práticas esportivas seja a adesão das pessoas significativas nestas práticas, no presente estudo poucas crianças tem esta vivência com seus pais. Pesquisa de Matsudo et al. (2003) relata que, em relação à estimulação da prática de atividades esportivas no meio infantil, os familiares são os fatores de influência mais importantes, sendo a família capaz de influenciar a escolha mais do que a escola e os amigos. Sallis et al. (1992) evidenciaram em seu estudo que crianças com mães ativas tem duas vezes mais chances de se tornarem ativas e três vezes mais chances se o pai for ativo fisicamente. A probabilidade aumenta para 5,8 vezes quando pai e mãe são fisicamente ativos.

A estrutura familiar, juntamente com seus hábitos diários, está sofrendo cada vez mais alterações, gerando com isso adaptações individuais e coletivas (NETO, 2001). O interesse futuro em atividades físicas, práticas esportivas e danças, geradores de uma melhor qualidade de vida, depende muito das experiências em níveis adequados na infância (VALENTINI; TOIGO, 2006). No contexto familiar atual a inatividade física prepondera; as consequências que estes novos hábitos familiares remetem ao menor envolvimento físico e motor das crianças. O que se percebe é que na atualidade os modelos de educação de crianças cada vez mais aceitos e difundidos são aqueles em que as crianças tem suas agendas preenchidas por diversas atividades institucionalizadas, muitas delas sendo pouco ativas (NETO, 2001, 2005), com pouca consideração a hábitos e práticas ativas diversificadas.

A família, embora considerada o fator de maior impacto na modelagem de comportamentos, tem se tornado uma instituição que pouco estimula um hábito de práticas ativas. Torna-se necessário considerar, portanto, que o envolvimento das pessoas mais próximas da criança é fator motivacional essencial para que o interesse por práticas ativas seja instigado. Quanto menos exemplos ativos a criança dispor, maiores as chances dela não praticar atividades motoras mais ativas e diversificadas no decorrer de toda a sua vida (MATSUDO et al., 2003). O ambiente familiar parece ter grande impacto no desenvolvimento das crianças, principalmente pelos fatores de ser o ambiente primário de socialização do indivíduo e o comportamento dos familiares ou cuidadores ser uma das principais referências para crianças em suas escolhas. Um ambiente que pouco estimula atividades de movimentação, portanto, pode influenciar negativamente no desenvolvimento de crianças e jovens.

\section{Considerações Finais}

Os resultados do presente estudo sugerem que a prática de atividades de ampla movimentação é restrita e pouco estimulada na rotina doméstica tanto de meninos quanto de 
meninas. No presente estudo as oportunidades de prática estavam restritas ao Programa de Educação pelo Esporte que era frequentado pela criança.

Pode-se perceber que na população aqui estudada a participação em programas de atividades físicas que viabilizem práticas motoras diversificadas, capazes de interferir positivamente para um desenvolvimento harmônico, é de suma importância uma vez que este se configura como um espaço essencial para os jogos e brinquedos de motricidade ampla. Essa importância se dá pela constatação de que há restrição e pouca estimulação no dia-a-dia dos participantes propiciado pela família, talvez decorrente da diminuição do espaço urbano para o lazer. Este fato gera uma demanda para a sociedade de propiciar ambientes que supram a carência motora vinda dos lares, compensando para a diminuição do espaço urbano.

Por fim, enfatiza-se que proporcionar experiências diversificadas, ativas e em contextos estimuladores é extremamente importante para criar na criança o interesse pela prática motora, que a conduzirá, posteriormente, à permanência em práticas esportivas que resultarão numa melhor qualidade de vida.

\section{THE CHILDHOOD DAILY ACTIVITIES AT THE HOME ENVIRONMENT}

Absctract: Children need to experience a variety of physical activities in their daily routines; family plays an important role in this process. The objective of this study was to compare boys and girls routine within the family environment. Subjects consisted of 32 children from 5 and 7 years old. Activities were assessed using the questionnaire developed by Serrano and Neto (1997). Boys and girls demonstrated similar and restrict engagement in vigorous activities at home. For both sexes, the family environment lack motivation for physical activity and positive models to promote children's engagement. To participate in sports education programs that promote a variety of physical activity practices are essential to address the lack of opportunities to be physical active observed at the home environment.

Key-words: Activities of Daily Living. Physical Activity. Sport Education Program.

\section{LA RUTINA DE LAS ATIVIDADES DE LOS NIÑOS EN EL ENTORNO FAMILIAR}

Resumen: Los niños necesitan experimentar distintos ejercicios en su cotidiano, la familia o los cuidadores desempeñan un papel importante en este proceso. El objetivo del estudio fue comparar la rutina de actividades infantiles en el contexto familiar. Los sujetos fueron 32 niños de edades comprendidas entre los 5 y 7 años. Se utilizó el cuestionario SERRANO y NETO (1997). Ellos mostraron similar participación, ceñido en las prácticas de amplio movimiento. Para ambos sexos, los entornos familiares son poco estimulantes, hay una falta de modelos a seguir por el desarrollo de las costumbres y prácticas de los responsables. La participación en los programas deportivos que estimulan las motoras variadas es esencial para compensar la futura escasez motora presente en los hogares.

Palabras-clave: ejercicios cotidiano. Prácticas físicas. Programa de Educación a través del Deporte

\section{Referências}

ALMEIDA, G.; VALENTINI, N. C., BERLEZE, A. Percepções de Competência: Um Estudo com Crianças e Adolescentes do Ensino Fundamental. Movimento, Porto Alegre, v. 15, n. 01, p. 71-97, janeiro/março de 2009. Disponível em: 
BARROS, S. S. H. Padrão de prática de atividades físicas de crianças em idade préescolar. 2005. 83 f. Dissertação (Mestrado em Educação Física). Universidade Federal de Santa Catarina, Florianópolis, 2005.

BERLEZE, A. Desenvolvimento motor de crianças obesas: uma análise de contexto. 2002. 120f. Dissertação (Mestrado em Ciências do Movimento Humano). Universidade Federal de Santa Maria, Santa Maria, 2002.

BERLEZE, A., HAEFFNER, L. S. B., VALENTINI, N. C. Desempenho motor de crianças obesas: uma investigação do processo e produto de habilidades motoras fundamentais. Revista Brasileira de Cineantropometria e Desempenho Humano; v. 9, n. 2, 2007.

BRAUNER, L.; VALENTINI, N. C. Análise do desempenho motor de crianças participantes de um programa de atividades físicas. Revista da Educação Física/UEM, Maringá, v. 20, n. 2, p. 205-216, 2 trim. 2009.

BRONFENBRENNER, U. A ecologia do desenvolvimento humano: experimentos naturais e planejados. Porto Alegre: Artes Médicas, 1996.

DELORS, J. Educação um tesouro a descobrir. Relatório para a Unesco da Comissão Internacional sobre a Educação para o Século XXI. 6. ed. Tradução José Carlos Eufrázio. São Paulo: Cortez, 2001.

DESSEN, M. A., POLONIA, A. C. A família e a escola como contextos de desenvolvimento humano. Paidéia (Ribeirão Preto) vol.17 no. 36. Ribeirão Preto Jan./Apr. 2007.

FILGUEIRA, J. C. M., PERIM G. L., OLIVEIRA, A. A. B. Apresentação. In: OLIVEIRA, A. A. B., PERIM, G. L. (org). Fundamentos pedagógicos do Programa Segundo Tempo: da reflexão à prática. Maringá: Eduem, pg 7-16. 2009.

GUEDES D. P., GUEDES J. E. R. P. Controle de peso corporal: composição corporal, atividade física e nutrição. $1^{\mathrm{a}}$ ed. Londrina-Paraná: Midiograf,1998.

KREBS, R. J. Urie Bronfenbrenner e a ecologia do desenvolvimento humano. Santa Maria, Casa Editorial, 1995a.

KREBS, R. J. A teoria da ecologia do desenvolvimento humano, de Urie Bronfenbrenner. In: Krebs, Rui J. (org). Desenvolvimento Humano: teorias e estudos. Santa Maria: Casa Editorial, 1995b.

MALHO, M. J. A criança e a cidade. Independência de mobilidade e representação sobre o espaço urbano. In: Congresso Português de Sociologia - Sociedades Contemporâneas Reflexividade e Acção. 5, 2004, Braga. Actas... Braga: Universidade do Minho, 2004. p. 4956.

MARCELlinO, N. C. Estudos do lazer: uma introdução. 4 ed. Campinas, SP. Editora Autores Associados, 2006. 
MARTINS, E., SZYMASNKI, H. A abordagem ecológica de Urie Bronfenbrenner em estudos com famílias. Estudos e pesquisas em Psicologia, UERJ, RJ, ano 4, n. 1, 1 semestre, 2004.

MATSUDO, V. K. R. et al. "Construindo" saúde por meio da atividade física em escolares. Revista Brasileira de Ciência e Movimento, Taguatinga, DF, v. 11, n. 4, p. 111-118, out/dez 2003.

MELO, J. P., DIAS, J. C. N. S. N. Fundamentos do Programa Segundo Tempo: entrelaçamentos do Esporte, do desenvolvimento humano, da cultura e da educação. In: OLIVEIRA, A. A. B., PERIM, G. L. (org). Fundamentos pedagógicos do Programa Segundo Tempo: da reflexão à prática. Maringá: Eduem, pg 17-44. 2009.

NETO, C. A educação motora e as "culturas de infância": importância da educação física e desporto no contexto escolar. Faculdade de Motricidade Humana. Universidade Técnica de Lisboa, 2001.

NETO, C. Neto, C. (2004). Desenvolvimento da motricidade e as culturas da infância. In W. Moreira \& R. Simões (Orgs.). Educação física. Intervenção e Conhecimento científico (pp. 35-50). Piracicaba - Brasil: Editora Unimep.

NETO, C. Jogo na Infância e Desenvolvimento Psicomotor. Faculdade de Motricidade Humana. Universidade Técnica de Lisboa, 2005.

PALMA, M. S. et al. Estilos de ensino e aprendizagem motora: implicações para a prática. In: OLIVEIRA, A. A. B., PERIM, G. L. (org). Fundamentos pedagógicos do Programa Segundo Tempo: da reflexão à prática. Maringá: Eduem, 2009. p. 89-114.

PATE, R. R., SIRARD, J. Physical activity and young people. Topics in Nutrition Hershey Foods Corporation, 8, 1-18, 2000.

PIAGET, J. A representação do espaço na criança. Porto Alegre, Artes Médicas (11-59), 1993.

RODRIGUES, F. M. G., PESSOA, V. M., SILVA, S. M. Verificação no nível de independência de mobilidade de crianças. Movimentum - Revista Digital de Educação Física Ipatinga: Unileste-MG. V. 2, N.2 - Ago.dez. 2007.

RUBINSTEIN, S., RAMALHO, M. H. S., NETTO, F. C. O desenvolvimento da criança com Paralisia Cerebral no ambiente familiar. Movimento, Porto Alegre, v. 8, n. 3, p. 33-45, setembro/dezembro 2002.

SALLIS J. F. et al. Parent behavior in relation to physical activity and fitness in 9-year-olds. American Journal of Diseases of Children, v. 146, p. 1383-1388, 1992. 
SANDERS, S. W. Ativos para a vida: programas de movimento adequados ao desenvolvimento da criança. Porto Alegre: Artmed, 2005

SANTOS, S., DANTAS, L., OLIVEIRA, J. A. Desenvolvimento motor de crianças, de idosos e de pessoas com transtorno da coordenação. Revista Paulista de Educação Física, São Paulo, v. 18, p. 33-34, ago-2004.

SERRANO, J., NETO, C. As rotinas de vida diária das crianças com idades compreendidas entre os 7 e os 10 anos nos meios rural e urbano. In C. Neto (Ed.). O jogo e o desenvolvimento da criança. Lisboa: Edições FMH, 1997. p. 207-226.

SOUZA, V. B. A. Criança, sociedade e interdisciplinaridade. In R. Krebs, F. Copetti \& T. Beltram (Eds.). Discutindo o Desenvolvimento Infantil. Santa Maria - Brasil, SIEC - Santa Maria, 1998. p. 13-21.

VALENTINI, N. C. A influência de uma intervenção motora no desempenho motor e na percepção de competência de crianças com atrasos motores. Revista Paulista de Educação Física, São Paulo, v. 16, n. 1, p. 61-75, jan./jun. 2002a.

VALENTINI, N. C. Percepções de Competência e Desenvolvimento Motor de meninos e meninas: um estudo transversal. Movimento, Porto Alegre, v. 8, n. 2, p. 51-62. 2002 b.

VALENTINI, N. C.; RUDISSIL, M. E. Motivational Climate, Motor-Skill Development, and Perceived Competence: Two Studies of Developmentally Delayed Kindergarten Children. Journal of Teaching in Physical Education, v. 23, n. 3, p. 216-234, 2004a.

VALENTINI, N. C.; RUDISSIL, M. E. An Inclusive Mastery Climate Intervention and the Motor Skill Development of Children with and Without Disabilities. Adapted Physical Activity Quarterly, v. 21, n. 4, 2004 b.

VALENTINI, N. C.; TOIGO, A. M. Ensinando educação física nas séries inicias: desafios e estratégias. $2^{a}$ edição. Canoas, Unilasalle, 2006.

Recebido em: 20/06/2014

Revisado em: 28/10/2014

Aprovado em: 20/03/2015

Endereço para correspondência:

nadiacv@ esef.ufrgs.br

Nadia Cristina Valentini

Universidade Federal do Rio Grande do Sul, Escola Superior de Educação Física.

Rua Felizardo 750 - LAPEX sala 106b

Jardim Botânico

90690200 - Porto Alegre, RS - Brasil 